\title{
О ПОДХОДЕ К ОЦЕНКЕ ЭФФЕКТИВНОСТИ ФУНКЦИОНИРОВАНИЯ МЯСОПЕРЕРАБАТЫВАЮЩИХ КОМПАНИЙ НА ОСНОВЕ ИНФОРМАЦИИ МОНИТОРИНГА БАНКРОТСТВ
}

\author{
Д. С. Матусевич \\ Байкальский государственный университет, г. Иркутск, Российская Федерация
}

\section{Информация о статье}

Дата поступления

7 декабря 2017 г.

Дата принятия к печати

28 фревраля 2018 г.

Дата онлайн-размещения

30 марта 2018 г.

\section{Ключевые слова}

Анализ финнансово-

хозяйственной деятельности;

мониторинг банкротств;

мясоперерабатывающий

комплекс Иркутской области

\begin{abstract}
Аннотация
В статье рассматривается оценка эфффективности функционирования мясоперерабатывающих компаний через призму мониторинга банкротств. Приводится краткая историческая справка о банкротствах таких компаний в Иркутской области за 2000-2017 гг. Выделяются ключевые факторы, влияющие на стабильность работы мясоперерабатывающих компаний: размеры производственных запасов, дебиторская и кредиторская задолженность, привлеченные краткосрочные кредиты и их интегральный результат. Данные фракторы анализируются применительно к ряду крупнейших мясоперерабатывающих компаний Иркутской области (2012-2016 гг.), показывается взаимосвязь между этими фракторами и прекращением деятельности отдельных компаний. Даются предложения по разработке информационно-аналитической системы мониторинга банкротства компаний мясоперерабатывающей отрасли.
\end{abstract}

\section{ON THE APPROACH TO MEAT-PROCESSING COMPANIES PERFORMANCE EVALUATION BASED ON BANKRUPTCY MONITORING DATA}

\author{
Dmitry S. Matusevich \\ Baikal State University, Irkutsk, the Russian Federation
}

Article info

Received

December 7, 2017

Accepted

February 28, 2018

Available online

March 30, 2018

\section{Keywords}

financial and operating

performance analysis; bankruptcy monitoring; Irkutsk Oblast meatprocessing companies

\begin{abstract}
The article considers an issue of evaluation of meat-processing companies performance from the perspective of bankruptcy monitoring. A brief account of meat-processing companies bankruptcy in Irkutsk Oblast in 2000-2017 is given. Key factors that influence the stability of meat-processing company performance are outlined: inventory volume, receivables and payables, borrowings and their cumulative result. An analysis of these factors with regard to a number of biggest meat-processing companies of Irkutsk Oblast (for 2012-2016) is carried out and a relationship between the factors and the termination of business of several of them is demonstrated. Some suggestions on the development of an information analysis system of meat-processing companies bankruptcy monitoring are made.
\end{abstract}

Термин «банкротство»в экономической литературе используется довольно широко, но только судебное решение позволяет констатировать этот фракт. Поэтому более правильным будет говорить о финансовых затруднениях компании, которые могут привести к банкротству [1]. Таким образом, актуальность приобретает задача мониторинга финансовой и хозяйственной деятельности компаний в целях прогнозирования вероятности их банкротства.
Мясоперерабатывающая отрасль Иркутской области представлена одним крупным свинокомплексом и несколькими мясоперерабатывающими комбинатами (МПК), работающими, как правило, на привозном сырье.

На протяжении 1990-2000-х гг. произошла череда банкротств МПК в небольших городах Иркутской области (табл. 1), из которых только "Усольский мясокомбинат» смог реорганизоваться в ЗАО «Усольские мясопродукты». В 2013 г. ОАО «Падунский 
мясокомбинат» (г. Братск) объявило о введении конкурсного производства, в 2016 г. МУП «Мясной двор» (г. Бодайбо) - о ликвидации, в 2017 г. ЗАО «Иркутский мясокомбинат» остановило производство [2], а ЗАО «Сибирская агропромышленная компания» объявила о введении конкурсного производства'.

Таблица 1

Данные о прекращении деятельности МПК в Иркутской области

\begin{tabular}{|c|c|}
\hline Компания & $\begin{array}{c}\text { Год прекращения } \\
\text { деятельности }\end{array}$ \\
\hline $\begin{array}{l}\text { ОАО «Мясокомбинат } \\
\text { «Култукский» }\end{array}$ & 2003 \\
\hline $\begin{array}{l}\text { ОАО «Мясокомбинат } \\
\text { «Тулунский» }\end{array}$ & 2003 \\
\hline $\begin{array}{l}\text { ОАО «Мясокомбинат } \\
\text { «Зиминский» }\end{array}$ & 2004 \\
\hline $\begin{array}{l}\text { ОАО «Мясоперерабатывающий } \\
\text { комбинат «Железногорский» }\end{array}$ & 2005 \\
\hline $\begin{array}{l}\text { ЗАО «Усть-Илимский мясоком- } \\
\text { бинат» }\end{array}$ & 2006 \\
\hline $\begin{array}{l}\text { ОАО «Мясокомбинат «Черем- } \\
\text { ховский» }\end{array}$ & 2006 \\
\hline $\begin{array}{l}\text { ОАО «Мясокомбинат «Нижне- } \\
\text { удинский» }\end{array}$ & 2007 \\
\hline \multicolumn{2}{|c|}{$\begin{array}{l}\text { Источник: Сведения о государственной регистра- } \\
\text { юридических лиц, индивидуальных предприни- } \\
\text { гелей, крестьянских (фермерских) хозяйств. URL: } \\
\text { s: //egrul.nalog.ru. }\end{array}$} \\
\hline
\end{tabular}

Для понимания текущей ситуации и оценки влияния отдельных факторов на мясоперерабатывающий комплекс Иркутской области с точки зрения мониторинга банкротств необходимо провести анализ их имущества и обязательств. Как показано в [3], классический анализ финансово-хозяйственной деятельности компании достаточно хорошо описывает и интерпретирует сложившуюся ситуацию.

Для рассмотрения выбраны следующие крупные составляющие активов и пассивов:

- производственные запасы - мясо, оболочка, пищевые добавки, показывающие продолжительность работы МПК без новых поставок, сглаживающие негативные эффректы от эпидемиологической ситуации у поставщиков, волатильность валютного рынка (поскольку ощутимая часть сырья завозится из-за границы) и т. п.;

- дебиторская и кредиторская задолженность и использование заемных ресурсов,

${ }^{1}$ Сведения о государственной регистрации юридических лиц, индивидуальных предпринимателей, крестьянских (фермерских) хозяйств. URL: https: / /egrul.nalog.ru. характеризующих финансовую независимость МПК;

- влияние первых двух составляющих на рентабельность МПК [3-7].

Рассмотрим запасы мясоперерабатывающих компаний Иркутской области. Из табл. 2 видно, что каждая компания либо поддерживает их примерно на одинаковом уровне, либо старается увеличить. Глядя на негативную динамику запасов «Иркутского мясокомбината», можно сказать, что точкой отсчета до прекращения производства стал 2014 год.

Доля производственных запасов Таблица 2 в общем имуществе крупнейших мясоперерабатывающих компаний Иркутской области

\begin{tabular}{|c|c|c|c|c|c|}
\hline \multirow{2}{*}{ МПК } & \multicolumn{5}{|c|}{ Доля запасов, \% } \\
\hline & 2012 & 2013 & 2014 & 2015 & 2016 \\
\hline $\begin{array}{l}\text { «Иркутский } \\
\text { мясокомбинат» }\end{array}$ & 29 & 30 & 16 & 14 & 24 \\
\hline $\begin{array}{l}\text { Мясоперера- } \\
\text { батывающий } \\
\text { комбинат } \\
\text { «Ангарский» }\end{array}$ & 48 & 41 & 46 & 43 & 32 \\
\hline $\begin{array}{l}\text { «Сибирская } \\
\text { агропромышлен- } \\
\text { ная компания» }\end{array}$ & $\cdots$ & 49 & 59 & 59 & 15 \\
\hline $\begin{array}{l}\text { «Усольские } \\
\text { мясопродукты» }\end{array}$ & 20 & 31 & $\cdots$ & 31 & 47 \\
\hline $\begin{array}{l}\text { «Усольский } \\
\text { свинокомплекс» }\end{array}$ & 43 & 52 & 43 & 54 & 50 \\
\hline
\end{tabular}

Источник: данные бухгалтерской отчетности, предоставляемые по запросам пользователей. URL: http://www.gks.ru/accounting_report.

Классический анализ финансово-хозяйственной деятельности компании [4-7] относит запасы сырья к группе «АЗ - медленнореализуемые активы», считая их чрезмерное количество проблемой для компании. С одной стороны, применительно к мясоперерабатывающей отрасли можно согласиться с этим утверждением, поскольку определенная часть запасов куплена на кредитные средства или с отсрочкой платежа. С другой стороны, наличие запасов обеспечивает компаниям стабильный выпуск готовой продукции и сглаживает межсезонные колебания в поставках.

В [8-10] для исследования эфффективности управления запасами предлагается следующая формула:

$$
\underset{\text { запасов, дней }}{\text { Оборачиваемость }}=\frac{(\text { Запасы на начало периода }+ \text { Запасы на конец периода }) / 2}{\text { Себестоимость продукции }} \cdot 360 \text { дней. }
$$


В табл. 3 приведены расчеты оборачиваемости запасов для ряда МПК Иркутской области. Исходя из них можно вывести некие границы в части управления запасами, понимание и соблюдение которых позволят компаниям найти баланс между размером запасов (замораживанием оборотных средств) и бесперебойным производством. Например, для мясоперерабатывающих компаний, работающих на привозном сырье, в качестве нижней границы можно принять цифру 90-100 дней, или примерно три - три с половиной месяца. Там же видно, что ситуация вокруг «Иркутского мясокомбината» берет свое начало уже в 2013 г., когда было зафиксировано сокращение доли запасов сырья (см. табл. 2).

Таблица 3

Оборачиваемость запасов крупнейших мясоперерабатывающих компаний Иркутской области батывающих компаний Иркутской области.
Доля дебиторской задолженности в общем имуществе крупнейших мясоперерабатывающих компаний Иркутской области

\begin{tabular}{|l|r|r|r|r|r|}
\hline \multirow{2}{*}{ МПК } & \multicolumn{5}{|c|}{ Доля дебиторской } \\
\cline { 2 - 6 } & 2012 & 2013 & 2014 & 2015 & 2016 \\
\hline $\begin{array}{l}\text { «Иркутский } \\
\text { мясокомбинат» }\end{array}$ & 60 & 59 & 67 & 67 & 17 \\
\hline $\begin{array}{l}\text { Мясоперерабаты- } \\
\text { вающий комбинат } \\
\text { «Ангарский» }\end{array}$ & 16 & 16 & 14 & 16 & 13 \\
\hline $\begin{array}{l}\text { «Сибирская агропро- } \\
\text { мышленная компания» }\end{array}$ & $\ldots$ & 14 & 7 & 14 & 5 \\
\hline $\begin{array}{l}\text { «Усольские } \\
\text { мясопродукты» }\end{array}$ & 24 & 24 & $\ldots$ & 41 & 30 \\
\hline $\begin{array}{l}\text { «Усольский } \\
\text { свинокомплекс» }\end{array}$ & 4 & 2 & 5 & 4 & 2 \\
\hline
\end{tabular}
предоставляемые по запросам пользователей. URL: http://www.gks.ru/accounting_report.

Исходя из данных табл. 4 и понимания характера образования дебиторской задолженности можно констатировать следующие особенности рынка мясной и колбасной продукции Иркутской области:

1. Наличие собственной торговой сети "Усольского свинокомплекса" позволяет исключить дебиторскую задолженность как значимый фактор, хотя, возможно, это формальный факт принятой учетной политики компании.

2. Предоставление торговым сетям своей готовой продукции в долг, с одной стороны, позволяет некоторым компаниям занять большую долю рынка, но одновременно это наносит двойной вред всем МПК Иркутской области. Во-первых, компании лишаются собственных оборотных средств и начинают прибегать к кредитным ресурсам. Соотнеся данные табл. 4 и 7 (наличие фрактов отрицательной рентабельности), можно сделать выводы, что подобная практика вредит больше самим компаниям, но переломить тенденцию им будет крайне сложно. Во-вторых, торговые сети получают возможность манипулировать рынком в собственных интересах, вынуждая других игроков следовать этим правилам.

В [8-10] для исследования эфффективности управления дебиторской задолженностью предлагается следующая формула:

$$
\begin{gathered}
\text { Оборачиваемость } \\
\text { дебиторской } \\
\text { задолженности, дней }
\end{gathered}=\frac{\left(\begin{array}{c}
\text { Дебиторская задолженность } \\
\text { на начало периода } \left.+\begin{array}{c}
\text { Дебиторская задолженность } \\
\text { на конец периода }
\end{array}\right) / 2
\end{array}\right.}{\text { Выручка }} \cdot 360 \text { дней. }
$$


Результаты вычислений представлены в табл. 5. Сравнивая результаты (по аналогии с оборачиваемостью запасов), можно определить границы, при соблюдении которых достигается баланс между нормированием дебиторской задолженности и разумными деловыми взаимоотношениями с оптовыми покупателями. В качестве нижней границы предлагается использовать планку в 20-40 дней.

Таблица 5

Оборачиваемость дебиторской задолженности крупнейших мясоперерабатывающих компаний Иркутской области

\begin{tabular}{|l|r|r|r|r|r|}
\hline \multirow{2}{*}{ МПК } & \multicolumn{4}{|c|}{$\begin{array}{l}\text { Оборачиваемость дебитор- } \\
\text { ской задолженности, дней }\end{array}$} \\
\cline { 2 - 7 } & 2012 & 2013 & 2014 & 2015 & 2016 \\
\hline $\begin{array}{l}\text { «Иркутский } \\
\text { мясокомбинат» }\end{array}$ & 104 & 125 & 140 & 194 & 147 \\
\hline $\begin{array}{l}\text { Мясоперерабаты- } \\
\text { вающий комбинат } \\
\text { «Ангарский» }\end{array}$ & 31 & 32 & 31 & 31 & 31 \\
\hline $\begin{array}{l}\text { «Сбирская агропро- } \\
\text { Мышленная компания» }\end{array}$ & $\ldots$ & 29 & 24 & 20 & 71 \\
\hline $\begin{array}{l}\text { «Усольские } \\
\text { мясопродукты» }\end{array}$ & 26 & 33 & $\ldots$ & 50 & 64 \\
\hline $\begin{array}{l}\text { «Усольский } \\
\text { свинокомплекс» }\end{array}$ & 13 & 9 & 11 & 13 & 9 \\
\hline
\end{tabular}

Источник: данные бухгалтерской отчетности, предоставляемые по запросам пользователей. URL: http://www.gks.ru/accounting_report.

В табл. 6 представлена информация о доле кредиторской задолженности в пассивах некоторых компаний Иркутской области. Особенностью кредиторской задолженности мясоперерабатывающей отрасли является задолженность перед поставщиками мяса, но поскольку взаимодействие между поставщиками и МПК носит долговременный характер, то эту компоненту кредиторской задолженности можно считать нетоксичной для компаний. Однако в этом случае компании должны строго соблюдать платежную дисциплину.

Таблица 6

Доля кредиторской задолженности и краткосрочных кредитов в пассивах крупнейших мясоперерабатывающих компаний Иркутской области

\begin{tabular}{|l|c|c|c|c|c|}
\hline \multirow{2}{*}{ МПК } & \multicolumn{5}{|c|}{ Доля кредиторской } \\
& \multicolumn{5}{|c|}{ кадолженностиккраткосрочных } \\
\cline { 2 - 6 } & 2012 & 2013 & 2014 & 2015 & 2016 \\
\hline $\begin{array}{l}\text { «Икутский } \\
\text { мясокомбинат» }\end{array}$ & $12 / 25$ & $18 / 23$ & $17 / 26$ & $19 / 26$ & $23 / 34$ \\
\hline $\begin{array}{l}\text { Мясоперера- } \\
\text { батывающий } \\
\text { комбинат } \\
\text { «Ангарский» }\end{array}$ & $11 / 25$ & $11 / 9$ & $9 / 19$ & $5 / 7$ & $4 / 0$ \\
\hline $\begin{array}{l}\text { «Сбирская аг- } \\
\text { ропромышлен- } \\
\text { ная компания» }\end{array}$ & $\ldots$ & $3 / 60$ & $6 / 25$ & $3 / 47$ & - \\
\hline
\end{tabular}

Окончание табл. 6

\begin{tabular}{|l|c|c|c|c|c|}
\hline \multirow{2}{*}{\multicolumn{1}{|c|}{ МПК }} & \multicolumn{5}{|c|}{ Доля кредиторской } \\
& \multicolumn{5}{|c|}{ кадолетитов, \% } \\
\cline { 2 - 7 } & 2012 & 2013 & 2014 & 2015 & 2016 \\
\hline $\begin{array}{l}\text { «Усольские } \\
\text { мясопродукты» }\end{array}$ & $28 / 37$ & $33 / 20$ & $\ldots$ & $17 / 31$ & $20 / 29$ \\
\hline $\begin{array}{l}\text { «Усольский } \\
\text { свинокомплекс» }\end{array}$ & $3 / 0$ & $2 / 0$ & $3 / 0$ & $4 / 0$ & $3 / 0$ \\
\hline \multicolumn{1}{|l|}{ Источник: данные бухгалтерской отчетности, }
\end{tabular}
предоставляемые по запросам пользователей. URL: http://www.gks.ru/accounting_report.

В [8-10] для исследования эфрфективности управления кредиторской задолженностью предлагается следующая формула:

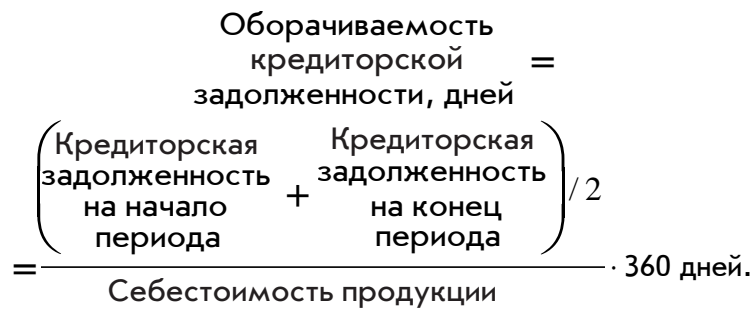

Результаты вычислений представлены в табл. 7.

Оборачиваемость

Таблица 7

кредиторской задолженности

крупнейших мясоперерабатывающих компаний Иркутской области

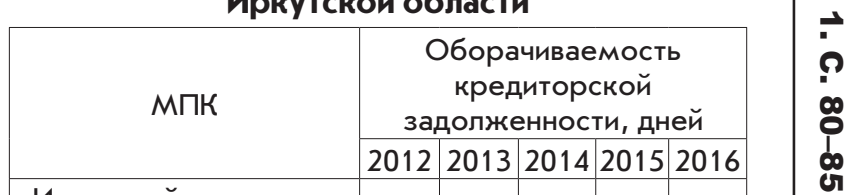

«Иркутский

мясокомбинат»

Мясоперерабаты-

вающий комбинат

«Ангарский»

«Сибирская агропро-

мышленная компания»

«Усольские

мясопродукты»

«Усольский

свинокомплекс»

\begin{tabular}{ll|l|l|l|}
27 & 38 & 44 & 58 & 70
\end{tabular}

Источник: данные бухгалтерской отчетности, предоставляемые по запросам пользователей. URL: http: //www.gks.ru/accounting_report.

Использование кредитных ресурсов для мясоперерабатывающей отрасли считается нормой, компании охотно берут кредиты на закупку мяса, оборудования, используя последнее в качестве залога (см. табл. 6). Вместе с тем необходимо соблюдать баланс между замораживанием оборотных средств и привлечением кредитных ресурсов. В табл. 8 представлена рентабельность МПК Иркутской области с учетом привлеченных кредитных средств. Как видно, привлечение краткосрочных кредитов уменьшает рентабельность ком- 
пании на 1-7 \%, а в некоторых случаях сводит ее до нуля, делая их деятельность рискованной.

Рентабельность основной деятельности крупнейших мясоперерабатывающих компаний Иркутской области с учетом кредитных средств в 2012-2016 гг., \%

\begin{tabular}{|l|c|c|c|}
\hline \multicolumn{1}{|c|}{ МПК } & $\begin{array}{c}\text { Без учета } \\
\text { кредитных } \\
\text { средств }\end{array}$ & $\begin{array}{c}\text { С учетом } \\
\text { кредитных } \\
\text { средств* }\end{array}$ & $\begin{array}{c}\text { Изме- } \\
\text { нение }\end{array}$ \\
\hline $\begin{array}{l}\text { с** } \\
\text { «Иркутский } \\
\text { мясокомбинат» }\end{array}$ & $-6,8 \ldots 1,7$ & $-10,6 \ldots 0$ & $1,4 \ldots 4,5$ \\
\hline $\begin{array}{l}\text { Мясоперерабаты- } \\
\text { вающий комбинат } \\
\text { «Ангарский» }\end{array}$ & $4,7 \ldots 11,0$ & $2,7 \ldots 10,5$ & $0 \ldots 0,8$ \\
\hline $\begin{array}{l}\text { «Сибирская агро- } \\
\text { промышленная ком- } \\
\text { пания» (без 2016г.) }\end{array}$ & $4,4 \ldots 7,8$ & $-1,3 \ldots 0,9$ & $5,7 \ldots 6,9$ \\
\hline $\begin{array}{l}\text { «Усольские } \\
\text { мясопродукты» }\end{array}$ & $1,8 \ldots 4,1$ & $1,1 \ldots 4,0$ & $0,1 \ldots 2,1$ \\
\hline $\begin{array}{l}\text { «Усольский } \\
\text { свинокомплекс» }\end{array}$ & $17,4 \ldots 23,3$ & - & - \\
\hline
\end{tabular}

Отношение строки 22003 «Прибыль (убыток) от продаж...» к строке 21103 «Выручка....» бухгалтерской отчетности.

"О Отношение разницы между строками 22003 «Прибыль (убыток) от продаж...» и 233303 «Проценты к уплате...» к строке 21103 «Выручка...» бухгалтерской отчетности. Разница между столбцами 2 и 3.

Источник: данные бухгалтерской отчетности, предоставляемые по запросам пользователей. URL: http: / / www.gks.ru/accounting_report.
Таким образом, для построения информационно-аналитической системы мониторинга банкротства мясоперерабатывающей отрасли (или отдельной мясоперерабатывающей компании) необходимо отслеживать рассмотренные показатели:

- производственные запасы - фактическое наличие, доля в активах компании, оборачиваемость запасов;

- дебиторскую задолженность - задолженность по каждой группе покупателей (зависимые организации, торговые сети, бюджетные организации), доля в активах компании, оборачиваемость задолженности;

- кредиторскую задолженность - задолженность по каждой группе поставщиков, график и размеры платежей, доля в пассивах компании, оборачиваемость задолженности;

- привлеченные заемные средства характер имущества, под которое получен кредит, график и размеры платежей, возможность реструктуризации;

- рентабельность компании с учетом привлеченных заемных средств $[1 ; 11]$.

\section{СПИСОК ИСПОЛЬЗОВАННОЙ ЛИТЕРАТУРЫ}

1. Юсупова Н. И. Мониторинг банкротств с использованием методов интеллектуального анализа данных / Н. И. Юсупова, Е. О. Волик / / Вестник Уфимского государственного авиационного технического университета. - 2008. - № 2. - С. 71-79.

2. Оккерт Д. Что случилось с мясокомбинатом? / Д. Оккерт / / СМ-Номер один. - 2017. - 30 марта.

3. Матусевич Д. С. Оценка продовольственной безопасности предприятий мясоперерабатывающей отрасли (на примере Иркутской области) [Электронный ресурс] / Д. С. Матусевич // Baikal Research Journal. - 2016. - T. 7, № 4. - Режим доступа: http://brj-bguep.ru/reader/article.aspx?id=20849. - DOI: 10.17150/2411-6262.2016.7(4).14

4. Баканов М. И. Теория экономического анализа : учебник / М. И. Баканов, М. В. Мельник, А. Д. Шеремет. - 5-е изд., перераб. и доп. - М. : Финансы и статистика, 2007. - 536 с.

5. Ковалев В. В. Анализ баланса, или как понимать баланс / В. В. Ковалев, Вит. В. Ковалев. - М. : Проспект, 2009. - 448 с.

6. Шеремет А. Д. Анализ и диагностика финансово-хозяйственной деятельности предприятия / А. Д. Шеремет. - М. : Инфра-М, 2009. - 366 c.

7. Доронина Ф. Х. Анализ финансового равновесия активов и пассивов баланса - основа оценки финансовой устойчивости и платежеспособности предприятия / Ф. Х. Доронина // Вестник Московского университета им. С. Ю. Витте. Сер. 1: Экономика и управление. - 2015. - № 4 (15). - С. 3-7.

8. Герасименко А. Финансовая отчетность для руководителей : [в 2 кн.] / А. Герасименко. - 2-е изд. М. : Альпина Паблишер, 2011. - Кн. 1. - 280 с.

9. Герасименко А. Финансовая отчетность для руководителей : [в 2 кн.] / А. Герасименко. - 2-е изд. М. : Альпина Паблишер, 2011. - Кн. 2. - 296 с.

10. Герасименко А. Финансовая отчетность для руководителей и начинающих специалистов : практ. пособие / А. Герасименко ; под ред. М. Савиной. - М. : Альпина Паблишер, 2016. - 432 с.

11. Грибанова Н. Н. Особенности планирования и прогнозирования компаний на основе инорормационных моделей [Электронный ресурс] / Н.Н.Грибанова, А. Ф. Шуплецов / / Baikal Research Journal. - 2017. T. 8, № 3. - Режим доступа: http://brj-bquep.ru/reader/article.aspx?id=21734. — DOI: 10.17150/24116262.2017.8(3).8.

\section{REFERENCES}

1. Yusupova N. I., Volik E. O. Bankruptcy monitoring by means of data mining techniques. Vestnik Ufimskogo gosudarstvennogo aviatsionnogo tekhnicheskogo universiteta = Ufa State Aviation Technical University, 2008, no. 2, pp. 71-79. (In Russian). 
2. Okkert D. What's wrong with the meat processing plant? SM-Nomer odin, 2017, no. 12. (In Russian).

3. Matusevich D. S. Assessing food security of meat-processing companies (as illustrated by Irkutsk Oblast). Baikal Research Journal, 2016, vol. 7, no. 4. Available at: http://brj-bguep.ru/reader/article. aspx?id=20849. DOI: 10.17150/2411-6262.2016.7(4).14. (In Russian).

4. Bakanov M. I., Melnik M. V., Sheremet A. D. Teoriya ekonomicheskogo analiza [Economic Analysis Theory]. $5^{\text {th }}$ ed. Moscow, Finansy i statistika Publ., 2007. 536 p.

5. Kovalev V. V., Kovalev Vit. V. Analiz balansa, ili kak ponimat' balans [Balance sheet analysis or how to interpret financial statements]. Moscow, Prospekt Publ., 2009. $448 \mathrm{p}$.

6. Sheremet A. D. Analiz i diagnostika finansovo-khozyaistvennoi deyatel'nosti predpriyatiya [Analysis and assessment of financial and operating performance of an enterprise]. Moscow, Infra-M Publ., 2009. 366 p.

7. Doronina F. Kh. Analysis of the assets and liabilities financial balance - the basis of assessment of financial stability and solvency of an enterprise. Vestnik Moskovskogo universiteta imeni S. Yu. Vitte. Seriya 1: Ekonomika i upravlenie = Moscow Witte University Bulletin. Series 1: Economics and management, 2015, no. 4 (15), pp. 3-7. (In Russian).

8. Gerasimenko A. Finansovaya otchetnost' dlya rukovoditelei [Financial data reporting for executives]. $2^{\text {nd }}$ ed. Moscow, Al'pina Pablisher Publ., 2011. Vol. 1. 280 p.

9. Gerasimenko A. Finansovaya otchetnost' dlya rukovoditelei [Financial data reporting for executives]. $2^{\text {nd }}$ ed. Moscow, Al'pina Pablisher Publ., 2011. Vol. 2. 296 p.

10. Gerasimenko A.; Savina M. (ed.). Finansovaya otchetnost' dlya rukovoditelei i nachinayushchikh spetsialistov [Financial data reporting for executives and recent graduates]. Moscow, Al'pina Pablisher Publ., 2016. 432 p.

11. Gribanova N. N., Shupletsov A. F. Features of corporate planning and forecasting on the basis of information models. Baikal Research Journal, 2017, vol. 8, no 3. Available at: http://brj-bguep.ru/reader/ article. aspx?id=21734. DOI: 10.17150/2411-6262.2017.8(3).8. (In Russian).

\section{Информация об авторе}

Матусевич Дмитрий Сергеевич - аспирант, кафедра экономики предприятия и предпринимательской деятельности, Байкальский государственный университет, 664003, г. Иркутск, ул. Ленина, 11, e-mail:mds@bgu.ru.

\section{Для цитирования}

Матусевич Д. С. О подходе к оценке эффрективности функционирования мясоперерабатывающих компаний на основе информации мониторинга банкротств / Д. С. Матусевич / / Известия Байкальского государственного университета. - 2018. T. 28 , № 1. - C. $80-85$. - DOI: $10.17150 / 2500$ 2759.2018.28(1).80-85.

\section{Author}

Dmitry S. Matusevich - post-graduate student, Enterprise Economics and Entrepreneurship Department, Baikal State University, 11 Lenin St., 664003, Irkutsk, the Russian Federation, e-mail: mds@bgu.ru.

\section{For citation}

Matusevich D. S. On the Approach to Meat-Processing Companies Performance Evaluation Based on Bankruptcy Monitoring Data. Izvestiya Baykal'skogo gosudarstvennogo universiteta $=$ Bulletin of Baikal State University, 2018, vol. 28, no. 1, pp. 80-85. DOI: 10.17150/2500-2759.2018.28(1).80-85. (In Russian). 